\title{
A FURTHER EXPLORATION OF THE THREE DRIVEN APPROACHES TO COMBINATIONAL CREATIVITY
}

\author{
Han, Ji (1); Hua, Min (2); Shi, Feng (2,3); Childs, Peter R. N. (2) \\ 1: University of Liverpool; 2: Imperial College London; 3: The Alan Turing Institute
}

\begin{abstract}
Combinational creativity is a significant element of design in supporting designers to generate creative ideas during the early phases of design. There exists three driven approaches to combinational creativity: problem-, similarity- and inspiration-driven. This study provides further insights into the three combinational creativity driven approaches, exploring which approach could lead to ideas that are more creative in the context of practical product design. The results from a case study reveal that the problemdriven approach could lead to more creative and novel ideas or products compared with the similarityand inspiration-driven approach. Products originating from the similarity- and inspiration-driven approach are at comparable levels. This study provides better understanding of combinational creativity in practical design. It also delivers benefits to designers in improving creative idea generation, and supports design researchers in exploring future ideation methods and design support tools employing the concept of 'combination'.
\end{abstract}

Keywords: Creativity, Conceptual design, Design methods, Product Design, Combinational Creativity

Contact:

Han, Ji

University of Liverpool

Industrial Design

United Kingdom

ji.han@liverpool.ac.uk

Cite this article: Han, J., Hua, M., Shi, F., Childs, P.R.N. (2019) 'A Further Exploration of the Three Driven Approaches to Combinational Creativity', in Proceedings of the 22nd International Conference on Engineering Design (ICED19), Delft, The Netherlands, 5-8 August 2019. DOI:10.1017/dsi.2019.280 


\section{INTRODUCTION}

Designing for our future is challenging. Idea generation, also known as ideation, is one of the most crucial phases in new product design and development, taking a broad definition of product. Idea generation is the process of producing and communicating ideas which are considered as essential elements of thought in visual, concrete and abstract forms (Jonson, 2005). It is deemed to be the foundation of innovation and business success (Cash and Štorga, 2015; Sarkar and Chakrabarti, 2011). Creativity is closely related to idea generation in design. It is defined as the process by which something so judged (to be creative) is produced' (Amabile, 1983), 'the ability to produce work that is both novel (i.e. original, unexpected) and appropriate (i.e. useful, adaptive concerning task constraints)' (Sternberg and Lubart, 1998), and 'the production of novel, useful products' (Mumford, 2003). It is significant to produce ideas that are creative, as creativity supports problem-solving, initiates innovation, and benefits business performance (Childs and Fountain, 2011; Sarkar and Chakrabarti, 2011). Goldschmidt and Tatsa (2005) indicated good ideas are regarded as the source from which creativity springs. However, it is challenging to generate new ideas that are creative.

A variety of methods and tools have been explored to support designers in creative idea generation, for example, conventional ones such as brainstorming (Osborn, 1979) and SCAMPER (Eberle, 1996), advanced methods such as Deign-by-Analogy (Goldschmidt, 2001) and Bio-inspired design (Chakrabarti and Shu, 2010; Helms et al., 2009); computational tools such as DANE (Goel et al., 2012; Vattam et al., 2011), the B-Link (Chen et al., 2017; Shi et al., 2017), and the Retriever (Han et $a l ., 2018 b)$. In order to provide operational insights, it is significant to explore the crucial factors that could lead to ideas that are more creative.

Combinational creativity, which is a natural feature of the human brain, is the easiest method for humans to produce creative ideas (Boden, 2009). It generates creative ideas through associating familiar ideas which were previously unrelated or indirectly related (Boden, 2004). Three driven approaches, inspiration-, similarity- and problem-driven, which could produce combinational creative ideas were reported by Han et al. (2019). The three driven approaches could be used individually as well as synthetically. Among the three approaches, the problem-driven approach is the dominant one used in practical designs. The three approaches are considered as a set of ideation methods, as well as a theoretical basis for developing computational design support tools. However, which approach could lead to ideas that are more creative was not explored.

This study is a further exploration of that conducted by Han et al. (2019). The aim is to investigate which combinational creativity driven approach, problem-, similarity- or inspiration-driven, could lead to more creative ideas. In this study, 'more creative ideas' refers to ideas that are more creative in terms of degree and not quantity. This study will provide a better understanding of combinational creativity and design creativity in the context of practical product design. The research outcome could deliver positive effects to designers for enhancing creative idea generation at early design phases, as well as design researchers for exploring future design support tools.

The following section presents related work of this study, such as combinational creativity and the three driven approaches to combinational creativity. Section 3 describes the study conducted in this paper along with the results. Sections 4 and 5 provide discussions and conclusions, respectively.

\section{RELATED WORK}

\subsection{Combinational creativity}

Combinational creativity involves creating new ideas by exploring unfamiliar combinations of familiar ideas (Boden, 2004). An 'Apple Watch' composed of a watch and a data device is an instance of combinational creativity, albeit with a sophisticated operation system. Combinational creativity is an easy approach for humans to achieve creativity, as it is a natural aspect of human associative memory (Boden, 2009). Ward and Kolomyts (2010) indicated that the 'ideas' to be combined involve concepts, words, images and abstract ones such as musical styles. Yang and Zhang (2016) suggested that combining knowledge and ideas might be the best approach to fully using abundant information to produce creative ideas. Taura et al. (2007) and Nagai et al. (2009) considered combining nouns or concepts is a beneficial method to prompt creative ideation at early design phases. A number of researchers use the term 'combinational creativity' to describe what creativity is. For instance, Childs 
(2018) considered creativity is the outcome of the combination of some essential mental capabilities resulting from long periods of work with some mini-breakthroughs; Henriksen et al. (2014) defined creativity as the process of making alterations and new combinations with existing ideas; Frigotto and Riccaboni (2011) suggested combination is the nature of creativity. However, Simonton (2017) indicated that combining ideas could lead to 'combinational explosion', which consumes years to generate and assess all the possible combinations. Also, Ward $(1994,1995)$ revealed that concept combinations would lead to considerable difficulties.

Recently, there is an increasing number of research projects exploring combinational creativity, especially in the area of computational creativity in design. For instance, Bacciotti et al. (2016) came up with a computational approach of combining concept from different dimensions to identify scenarios of products; Georgiev et al. (2017) indicated a computational method of generating new scenes through the synthesis of existing scenes to support new product develop; Han et al. (2018a) explored an approach imitating aspects of human cognition in producing combinational creativity, and came up with a computational ideation support tool named the Combinator; Chen et al. (2018) demonstrated an artificial intelligent approach of producing combinational images by using GAN (Generative Adversarial Network).

\subsection{Three driven approaches to combinational creativity}

Han et al. (2019) have proposed three approaches, problem-, similarity- and inspiration-driven, which can produce combinational creative ideas. In the study, an idea is regarded as an object or the concept of an object. To be more precise, ideas are considered as the representations (such as attributes, functions and features) as well as the aesthetics of objects or concepts of objects. 'Objects' involve both physical objects and abstract objects such as design style. 'Aesthetics' include the physical shape as well as the notion of the figure of an object. Noun-noun combination, which is used in this study, is the conventional form of combinational creativity. Here, a noun can refer to a single noun words (such as 'cup') as well as a noun phrase (such as a 'coffee cup').

The problem-driven approach indicates that combinational creativity is driven by design problems (Han et al., 2019). A design problem is described as the gap between the existing situation of an object and its target (Taura and Nagai, 2013), while solving a design problem is to explore ideas, known as problem-solving ideas that can bridge the gap. Thereby, the problem-driven approach is described as producing target ideas by combining basic ideas and problem-solving ideas (Han et al., 2019). A practical example of this approach is the Anti-rain Ares designed by Gongniu Group, as shown in Figure 1(a). This embodies a rainproof socket combined of a socket, which is the basic idea, and an umbrella, which is the problem-solving idea.

The similarity-driven approach implies that combinational creativity is driven by similar representations between ideas (Han et al., 2019). As illustrated above, representations refer to attributes, functions and features. Earl and Eckert (2002) suggested that two designs are similar if they share a set of similar representations. Similar ideas are associated in the human brain commonly by identifying similar representations by learning and experience (Suzuki, 2005). The combination of similar ideas could be creative, despite being associated. Therefore, the similarity-driven approach is considered as producing a creative idea by combining a basic idea and a similar representation idea. A practical similarity-driven example is the Tongner designed by Daka, as shown in Figure 1(b), which is a combination of a pair of tongs (the basic idea) and a spatula (the similar representation idea).

In the inspiration-driven approach, combinational creativity is driven by sources of inspiration (Han et al., 2019). Inspiration is considered as a creative solution generation process in design, which integrates the use of various entities in various forms (Gonçalves et al., 2014). Experience, knowledge, examples, previous designs, design concepts, images, objects and phenomena are often served as sources of inspiration (Cai et al., 2010; Chan et al., 2015; Eckert and Stacey, 2000; Howard et al., 2011; Sio et al., 2015). Sources of inspiration are often used by designers to provoking creative idea generation, but Crilly and Cardoso (2017) indicated that these sources might constrain the designers' imagination. Han et al. (2019) suggested that sources of inspiration can be considered as inspirational ideas. Thereby, producing a creative idea by combining a basic idea and an inspirational idea is referred to as the inspiration-driven approach. Juicy Salif designed by Philippe Starck is an inspiration-driven instance combining a lemon squeezer (the basic idea) and a squid (the inspirational idea). 


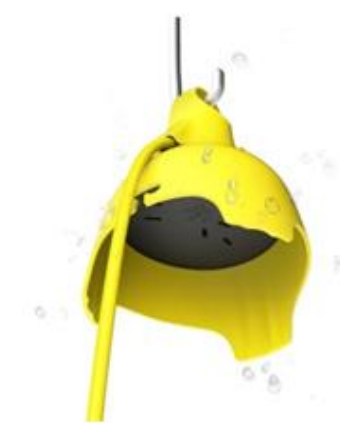

a. Anti-rain Ares

(The problem-driven approach)

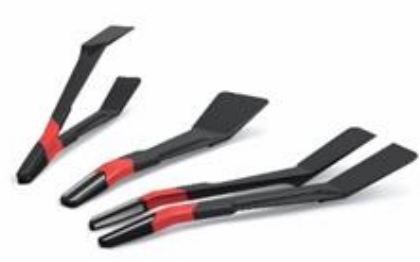

b. Tongner

(The similarity-driven approach)

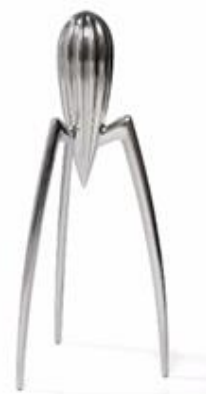

c. Juicy Salif

(The inspiration-driven approach)

Figure 1. Practical examples of the three driven approaches (adapted from (Han et al., 2019))

A noun-noun combinational idea is composed of a base idea (the basic idea) and an additive idea (a problem-solving idea, a similar representation idea, or an inspirational idea) (Han et al., 2019). A summary of the three driven approaches is shown below in Table 1. As shown in the table, the three driven approaches indicate three types of combinational creativity respectively, which are problemdriven, similarity-driven, and inspiration-driven combinational creativity. The three types of combinational creativity are driven by three different forces, alternatively, they are achieved by combining basic ideas with three different types of additive ideas, respectively.

Table 1. A summary of the three driven approaches (adapted from (Han et al., 2019))

\begin{tabular}{llll}
\hline Driven approaches & The bases & The additives & $\begin{array}{l}\text { Types of combinational } \\
\text { creativity }\end{array}$ \\
\hline $\begin{array}{l}\text { The problem-driven } \\
\text { approach }\end{array}$ & Basic idea & Problem-solving idea & $\begin{array}{l}\text { Problem-driven } \\
\text { combinational creativity }\end{array}$ \\
\hline $\begin{array}{l}\text { The similarity-driven } \\
\text { approach }\end{array}$ & Basic idea & Similar-representation idea & $\begin{array}{l}\text { Similarity-driven } \\
\text { combinational creativity }\end{array}$ \\
\hline $\begin{array}{l}\text { The inspiration-driven } \\
\text { approach }\end{array}$ & Basic idea & Inspirational idea & $\begin{array}{l}\text { Inspiration-driven } \\
\text { combinational creativity }\end{array}$ \\
\hline
\end{tabular}

Han et al. (2019) showed that the three driven approaches are widely used in practical designs through conducting a study. The three driven approaches can be used solely as well as synthetically by designers as a set of design methods for producing combinational creative ideas. The study indicated that the problem-driven approach is the dominant one for producing combinational creative ideas, while the similarity-driven approach is the least used one. However, which approach could lead to more creative ideas has not yet been explored. The next section investigates this issue through conducting a study.

\section{A FURTHER STUDY OF THE THREE DRIVEN APPROACHES}

\subsection{Study methods}

In order to explore which approach, problem-, similarity- or inspiration-driven, could produce ideas that are more creative in terms of degree, we have conducted a study involving practical designs. The practical design samples used in this study were from the research project conducted by Han et al. (2019), of which the samples were used to identify the three driven approaches. The practical designs, which are combinational creativity originated designs, were selected from the winners of international design awards or competitions, such as iF and the Red Dot, through purposive sampling. These practical designs are also known as samples as well as combinational designs in this paper.

The use of winners of design competitions in design creativity research is increasing in recent years and has achieved good results. For instance, Wang (2016) proposed an ideation method named winning formulas for metaphor design, Yilmaz et al. (2016) came up with 77 evidence-based design heuristics for ideation, Han et al. (2018c) investigated the relationships between the conceptual distances and the degree of creativity through exploring winners of design competitions. Although 
design competitions might lack rigorous creativity assessments, it is indicated that design competitions are creativity-oriented (Wang and Chan, 2010). Besides, novelty and usefulness, which are often used to assess design creativity (Chulvi et al., 2012; Diedrich et al., 2015; Sarkar and Chakrabarti, 2011), are top assessment criteria in design competitions (Hasdoğan, 2012). Thereby, the samples selected from top international design competitions are considered as creative (novel and useful) combinational ideas in this study.

We have employed expert evaluation in this study to measure the degree of creativity of combinational designs. Assessing a design is a multi-criteria decision-making process, which is commonly led by experts by using qualitative descriptions and subjective judgements (Zhai et al., 2009). In design creativity research, this method has been adopted in a number of studies, such as (Sarkar and Chakrabarti, 2011) and (Han et al., 2018c). Therefore, expert evaluation is a preferable method for design creativity assessment, despite the potential impacts caused by different experts' experience.

Using metrics to assess creativity is a common method in design research, but different researchers use various sets of metrics. For example, Shah et al. (2003) proposed novelty, quantity, variety and quality; López-Mesa et al. (2011) used variety, novelty, quantity and feasibility; Sarkar and Chakrabarti (2011) applied novelty and usefulness; Chiu and Shu (2012) used novelty, usefulness and cohesiveness. Some of the metrics are focused on measuring the creativity of a method or process, and others are used to measure a product or an output.

O'Quin and Besemer (1989) proposed a revision of the Creative Product Semantic Scale (CPSS) to measure creativity. This method is used for assessing the creativity of a product rather than a process, and it has been validated for several times (Chulvi et al., 2012). The creativity assessment method adopted in this study is the CPSS questionnaire proposed by Chulvi et al. (2012), which is mainly based on two parameters, novelty and usefulness or resolution. This questionnaire employs CPSS as the essential part of creativity assessment, and uses a seven-point Likert scale, ranging from 'low' to 'high', as shown in Figure 2. Evaluators need to score between bipolar pairs for each item involved in the questionnaire. The items referring to novelty and usefulness are mixed to avoid the evaluators' inertia. In order to help readers understand the questionnaire better, the rows in grey shadings represent usefulness pairs, while the others represent novelty pairs, as shown in Figure 2. The grey shadings were not shown to the evaluators involved in this study.

\begin{tabular}{|c|c|c|c|c|c|c|c|}
\hline & 1 & 2 & 3 & 4 & 5 & 6 & 7 \\
\hline Usual & & & & & & & Unusual \\
\hline Inoperable & & & & & & & Operable \\
\hline Commonplace & & & & & & & Astonishing \\
\hline Nonfunctional & & & & & & & Functional \\
\hline Customary & & & & & & & Surprising \\
\hline Overused & & & & & & & Fresh \\
\hline Unnecessary & & & & & & & Necessary \\
\hline Commonplace & & & & & & & Original \\
\hline Common & & & & & & & Astounding \\
\hline Unfeasible & & & & & & & Feasible \\
\hline Inappropriate & & & & & & & Appropriate \\
\hline Unusable & & & & & & & Usable \\
\hline Predictable & & & & & & & Novel \\
\hline Inadequate & & & & & & & Adequate \\
\hline Ineffective & & & & & & & Effective \\
\hline Inessential & & & & & & & Essential \\
\hline Useless & & & & & & & Useful \\
\hline Average & & & & & & & Revolutionary \\
\hline
\end{tabular}

Figure 2. Creative product semantic scale questionnaire (adapted from (Chulvi et al., 2012)) 


\subsection{Study process and results}

The set of samples, two-hundred practical combinational creativity orientated designs, used in this study are the same set used to evaluate the three driven approaches by Han et al. (2019). Therefore, the identification of combinational driven approaches used by different products is not required in this study. Five evaluators were involved in the evaluation in the study conducted by Han et al. (2019). In this study, it is considered that there is a consensus agreement if four out of the five evaluators had the same driven approach decisions on a product. Based on this, among the 200 samples selected, 97 products used the problem-driven approach solely, 55 products used the inspiration-driven approach solely, 23 products used the similarity driven approach solely, and the others used synthesised approaches. This result is in line with the overall findings indicated by Han et al. (2019), which is illustrated in the previous section. The aim of this study is to explore which driven approach could produce ideas that are more creative, and thereby synthesised approaches are not discussed.

Six designs from each, the problem-, similarity-, and inspiration-driven approach, were selected randomly to investigate which approach could lead to more creative ideas. Six design experts, three males and three females who have more than six years of experience on average $(S D=0.96)$, participated in this study voluntarily with intrinsic motivations. The number of experts might seem low, but there are no standard agreements on the number of experts for an assessment (Lai et al., 2006). Achiche et al. (2013) indicated that the number required for expert evaluators is far less than general evaluators. For example, only two experts were involved in the creativity evaluation study conducted by Charyton and Merrill (2009). The six expert evaluators are known as Experts 1 to 6 respectively in this study. The evaluators were provided with eighteen designs in total in a random order on a PDF document. The document involves the names, images, and text descriptions of the designs, respectively. An example of a selected sample is shown in Figure 3. No other information or material, except the CPSS questionnaire, were provided to the evaluators. The experts conducted the evaluation independently to increase the robustness of the scores. As illustrated previously, the CPSS questionnaire involves bipolar pairs of items on a seven-point scale. The creativity score of a product is the sum of the scores of all the items included, while the novelty and usefulness scores are the sums of the scores of novelty and usefulness items, respectively.
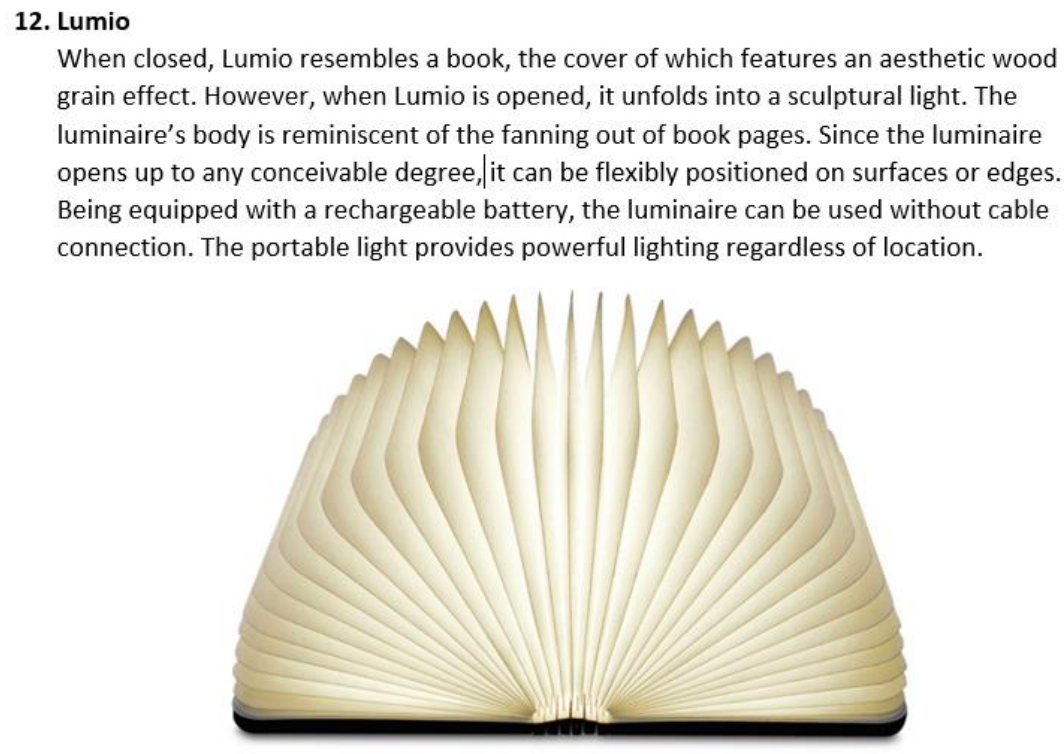

Figure 3. An example of a selected sample

A Cronbach's alpha test was conducted to measure the reliability of the evaluation results. Three types of combinational creative product samples were evaluated in this study: problem-driven $(\alpha=0.783)$, similarity-driven $(\alpha=0.725)$, and inspiration-driven $(\alpha=0.901)$. The values of Cronbach's alpha have indicated acceptable and excellent levels of internal consistency or reliability in the three product categories. Thereby, mean values of the scores rated by the six experts were used for further analysis. The study results, involving mean scores of novelty, usefulness, and the overall ratings of creativity of the three combinational driven approaches, are shown in Table 2. Note that SD in Table 2 refers to sample standard deviation. 
Table 2. The study results

\begin{tabular}{|l|c|c|c|}
\hline & Mean Creativity (SD) & Mean Novelty (SD) & Mean Usefulness (SD) \\
\hline Problem-Driven & $84.42(5.12)$ & $37.64(3.98)$ & $46.78(5.12)$ \\
\hline Similarity-Driven & $79.33(5.21)$ & $32.89(7.72)$ & $46.44(6.24)$ \\
\hline Inspiration-Driven & $81.11(10.13)$ & $35.47(8.18)$ & $45.64(4.25)$ \\
\hline
\end{tabular}

A Cohen's d test was conducted to measure the standardised differences among the mean creativity, novelty and usefulness scores of the problem-, similarity- and inspiration-driven design samples, respectively. The absolute values of the Cohen's d of mean creativity, novelty and usefulness are shown in Table 3-5, respectively. A Cohen's d value of 0.2 represents a 'small' effect size, 0.5 represents a 'moderate' effect size, and 0.8 refers to a 'large' effect size.

Table 3. Cohen's $d$ values of mean creativity

\begin{tabular}{|l|c|c|c|}
\hline \multicolumn{4}{|c|}{ Mean Creativity } \\
\hline & Problem-Driven & Similarity-Driven & Inspiration-Driven \\
\hline Problem-Driven & $\backslash$ & & \\
\hline Similarity-Driven & 0.99 - Large & $\backslash$ & \\
\hline Inspiration-Driven & 0.41 - Moderate & 0.22 - Small & $\backslash$ \\
\hline
\end{tabular}

Table 4. Cohen's $d$ values of mean novelty

\begin{tabular}{|l|c|c|c|}
\hline \multicolumn{4}{|c|}{ Mean Novelty } \\
\hline & Problem-Driven & Similarity-Driven & Inspiration-Driven \\
\hline Problem-Driven & $\backslash$ & & \\
\hline Similarity-Driven & 0.77 - Large & $\backslash$ & \\
\hline Inspiration-Driven & 0.34 - Moderate & 0.32 - Moderate & 1 \\
\hline
\end{tabular}

Table 5. Cohen's $d$ values of mean usefulness

\begin{tabular}{|l|c|c|c|}
\hline \multicolumn{4}{|c|}{ Mean Usefulness } \\
\hline & Problem-Driven & Similarity-Driven & Inspiration-Driven \\
\hline Problem-Driven & $\backslash$ & & \\
\hline Similarity-Driven & 0.06 - Small & $\backslash$ & \\
\hline Inspiration-Driven & 0.24 - Small & 0.15 - Small & 1 \\
\hline
\end{tabular}

\section{DIscussion}

The study results are shown in Table 2, and the Cohen's d values of mean creativity, novelty and usefulness scores are shown in Table 3-5, respectively. According to Table 2, the mean creativity score of the problem-driven combinational creative products, rated by the six experts, is higher than the products using the similarity-driven approach and the inspiration-driven approach. As shown in Table 3, the effect size between the mean creativity scores of the problem-driven products and the similarity-driven products is large $(d=0.99)$, while the effect size between the problem-driven products and the inspiration-driven products is moderate $(d=0.41)$. Comparing with the products using the similarity-driven approach, the mean creativity score of the products using the inspiration-driven approach is higher. However, the effect size between the two types is small $(d=0.22)$, which shows a small difference between the degrees of creativity of the similarity-driven products and the inspirationdriven products. Therefore, the products using the problem-driven approach are considered more creative than the products using the other two approaches. The degrees of creativity of the similarityand inspiration-driven products are at comparable levels. 
In terms of novelty, the mean score of the problem-driven products is higher than the similarity- and inspiration-driven products with large $(d=0.77)$ and moderate $(d=0.34)$ effect sizes, respectively. The mean novelty of the products originated by the inspiration-driven approach is higher than the ones using the similarity-driven approach, with a moderate effect size $(d=0.32)$. Thus, the problem-driven products are suggested to have a higher degree of novelty comparing with the others. The inspirationdriven products are moderately higher than the similarity-driven ones in terms of novelty.

There is little difference among the mean usefulness scores of the problem-, similarity-, inspirationdriven products. In addition, the effect sizes among the three types of products are small: problemsimilarity $(d=0.06)$, problem-inspiration $(d=0.24)$, similarity-inspiration $(d=0.15)$. Thereby, it is considered that the degrees of usefulness of all the types of combinational creativity driven products are at similar levels.

Concerning the study conducted, the sample products originated by using the problem-driven approach are considered more creative and novel than the ones using the similarity- and inspirationdriven approaches. Although, the inspiration-driven products are moderately more novel than the similarity-driven products, the differences in creativity and usefulness are small. Thus, the sample products originated by the inspirational- and similarity-driven approaches are regarded at similar degrees. Besides, there are no big differences among the degrees of the usefulness of the product using different driven approaches. This might be due to the limitation of using design competition winners as samples, as the winners are arguably more useful than the conventional products on the market. It is thereby suggested to use problem-solving ideas as additives or using the problem-driven approach to produce creative combinational ideas for new products during early design stages.

\section{CONCLUSIONS}

This paper has further explored three driven approaches to combinational creativity in the context of practical product design. The study has shown that the problem-driven approach could lead to outcomes that are more creative and novel compared with the other two approaches, while the inspiration-driven approach and the similarity-driven approach are at a comparable level, for the study concerned. The study has provided a better understanding of combinational creativity in design. The research outcome could support designers in selecting appropriate additive ideas and driven approaches to generate creative combinational ideas for new product design and development during the early phases of design. It could also support the exploration of future ideation methods, as well as the development of future computational design support tools that involve the element of 'combination', such as the combination of scenes (Georgiev et al., 2017) and the Combinator (Han et al., 2018a). A further study involving more samples and more experts is planned to produce additional insights.

\section{REFERENCES}

Achiche, S., Appio, F.P., McAloone, T.C. and Di Minin, A. (2013), "Fuzzy decision support for tools selection in the core front end activities of new product development", Research in Engineering Design, Vol. 24 No. 1, pp. 1-18. https://doi.org/10.1007/s00163-012-0130-4

Amabile, T.M. (1983), The Social Psychology of Creativity, Springer-Verlag, New York, USA.

Bacciotti, D., Borgianni, Y. and Rotini, F. (2016), “An original design approach for stimulating the ideation of new product features", Computers in Industry, Vol. 75 No. Supplement C, pp. 80-100.

Boden, M.A. (2004), The Creative Mind: Myths and Mechanisms, 2 edn, Routledge, London, UK.

Boden, M.A. (2009), “Computer models of creativity”, AI Magazine, Vol. 30 No. 3, pp. 23-34. http://dx.doi.org/10.1609/aimag.v30i3.2254

Cai, H., Do, E.Y.-L. and Zimring, C.M. (2010), "Extended linkography and distance graph in design evaluation: an empirical study of the dual effects of inspiration sources in creative design", Design Studies, Vol. 31 No. 2, pp. 146-168. https://doi.org/10.1016/j.destud.2009.12.003

Cash, P. and Storga, M. (2015), "Multifaceted assessment of ideation: using networks to link ideation and design activity", Journal of Engineering Design, Vol. 26 No. 10-12, pp. 391-415. https://doi.org/10.1080/09544828.2015.1070813

Chakrabarti, A. and Shu, L.H. (2010), "Biologically inspired design", Artificial Intelligence for Engineering Design, Analysis and Manufacturing, Vol. 24 No. 4, pp. 453-454. https://doi.org/10.1017/S0890060410000326

Chan, J., Dow, S.P. and Schunn, C.D. (2015), "Do the best design ideas (really) come from conceptually distant sources of inspiration?”, Design Studies, Vol. 36, pp. 31-58. https://doi.org/10.1016/j.destud.2014.08.001 
Charyton, C. and Merrill, J.A. (2009), “Assessing general creativity and creative engineering design in first year engineering students", Journal of Engineering Education, Vol. 98 No. 2, pp. 145-156.

Chen, L., Shi, F., Han, J. and Childs, P.R.N. (2017), "A Network-Based Computational Model for Creative Knowledge Discovery Bridging Human-Computer Interaction and Data Mining", ASME 2017 International Design Engineering Technical Conferences and Computers and Information in Engineering Conference, pp. V007T006A001. https://doi.org/10.1115/DETC2017-67228

Chen, L., Wang, P., Shi, F., Han, J. and Childs, P. (2018), “A computational approach for combinational creativity in design", DS92: Proceedings of the DESIGN 2018 15th International Design Conference, pp. 1815-1824. https://doi.org/10.21278/idc.2018.0375

Childs, P. and Fountain, R. (2011), "Commercivity", DS 69: Proceedings of E\&PDE 2011, the 13th International Conference on Engineering and Product Design Education, London, UK, 08.-09.09.2011.

Childs, P.R.N. (2018), Mechanical Design Engineering Handbook, 2nd edn, Butterworth-Heinemann, Oxford, UK.

Chiu, I. and Shu, L.H. (2012), "Investigating effects of oppositely related semantic stimuli on design concept creativity”, Journal of Engineering Design, Vol. 23 No. 4, pp. 271-296. https://doi.org/10.1080/09544828.2011.603298

Chulvi, V., Sonseca, Á., Mulet, E. and Chakrabarti, A. (2012), “Assessment of the relationships among design methods, design activities, and creativity”, Journal of Mechanical Design, Vol. 134 No. 11, pp. 111004111004-111011. https://doi.org/10.1115/1.4007362

Crilly, N. and Cardoso, C. (2017), "Where next for research on fixation, inspiration and creativity in design?", Design Studies, Vol. 50, pp. 1-38. https://doi.org/10.1016/j.destud.2017.02.001

Diedrich, J., Benedek, M., Jauk, E. and Neubauer, A.C. (2015), “Are creative ideas novel and useful?", Psychology of Aesthetics, Creativity, and the Arts, Vol. 9 No. 1, pp. 35-40. https://doi.org/10.1037/a0038688

Earl, C.F. and Eckert, C.M. (2002), “The structure of similarity in design”, Computer-Based Design: Engineering Design Conference 2002, pp. 527-536.

Eberle, B. (1996), Scamper on: Games for Imagination Development, Prufrock Press Inc, Waco, USA.

Eckert, C. and Stacey, M. (2000), "Sources of inspiration: a language of design”, Design Studies, Vol. 21 No. 5, pp. 523-538. https://doi.org/10.1016/S0142-694X(00)00022-3

Frigotto, M.L. and Riccaboni, M. (2011), "A few special cases: Scientific creativity and network dynamics in the field of rare diseases”, Scientometrics, Vol. 89 No. 1, pp. 397-420. https://doi.org/10.1007/s11192-0110431-9

Georgiev, G.V., Sumitani, N. and Taura, T. (2017), "Methodology for creating new scenes through the use of thematic relations for innovative designs", International Journal of Design Creativity and Innovation, Vol. 5 No. 1-2, pp. 78-94. https://doi.org/10.1080/21650349.2015.1119658

Goel, A.K., Vattam, S., Wiltgen, B. and Helms, M. (2012), "Cognitive, collaborative, conceptual and creative Four characteristics of the next generation of knowledge-based CAD systems: A study in biologically inspired design", Computer-Aided Design, Vol. 44 No. 10, pp. 879-900. https://doi.org/10.1016/j.cad.2011.03.010

Goldschmidt, G. (2001), "Visual Analogy - a Strategy for Design Reasoning and Learning”, In: Design Knowing and Learning: Cognition in Design Education, Elsevier Science, Oxford, pp. 199-219.

Goldschmidt, G. and Tatsa, D. (2005), "How good are good ideas? Correlates of design creativity", Design Studies, Vol. 26 No. 6, pp. 593-611. https://doi.org/10.1016/j.destud.2005.02.004

Gonçalves, M., Cardoso, C. and Badke-Schaub, P. (2014), "What inspires designers? Preferences on inspirational approaches during idea generation", Design studies, Vol. 35 No. 1, pp. 29-53.

Han, J., Shi, F., Chen, L. and Childs, P.R.N. (2018a), "The combinator - a computer-based tool for creative idea generation based on a simulation approach", Design Science, Vol. 4, pp. e11. https://doi.org/10.1017/dsj.2018.7

Han, J., Shi, F., Chen, L. and Childs, P.R.N. (2018b), “A computational tool for creative idea generation based on analogical reasoning and ontology”, Artificial Intelligence for Engineering Design, Analysis and Manufacturing, Vol. 32 No. 4, pp. 462-477. https://doi.org/10.1017/S0890060418000082

Han, J., Shi, F., Chen, L. and Childs, P.R.N. (2018c), "The Conceptual Distances between Ideas in Combinational Creativity", DS92: Proceedings of the DESIGN 2018 15th International Design Conference. https://doi.org/10.21278/idc.2018.0264

Han, J., Park, D., Shi, F., Chen, L., Hua, M. and Childs, P.R. (2019), "Three driven approaches to combinational creativity: Problem-, similarity- and inspiration-driven”, Proceedings of the Institution of Mechanical Engineers, Part C: Journal of Mechanical Engineering Science. Vol. 233 No. 2, pp. 373-384. https://doi.org/10.1177/0954406217750189

Hasdoğan, G. (2012), "Characterising turkish design through good design criteria: the case of design turkey industrial design awards", METU Journal of the Faculty of Architecture, Vol. 29, pp. 171-191.

Helms, M., Vattam, S.S. and Goel, A.K. (2009), "Biologically inspired design: process and products", Design Studies, Vol. 30 No. 5, pp. 606-622. https://doi.org/10.1016/j.destud.2009.04.003 
Henriksen, D., Mishra, P. and the Deep-Play Research, G. (2014), “Twisting knobs and connecting things: Rethinking technology \& creativity in the 21 st century", TechTrends, Vol. 58 No. 1, pp. 15-19.

Howard, T.J., Culley, S. and Dekoninck, E.A. (2011), "Reuse of ideas and concepts for creative stimuli in engineering design”, Journal of Engineering Design, Vol. 22 No. 8, pp. 565-581. https://doi.org/10.1080/09544821003598573

Jonson, B. (2005), "Design ideation: the conceptual sketch in the digital age", Design Studies, Vol. 26 No. 6, pp. 613-624. https://doi.org/10.1016/j.destud.2005.03.001

Lai, H.-H., Lin, Y.-C., Yeh, C.-H. and Wei, C.-H. (2006), "User-oriented design for the optimal combination on product design", International Journal of Production Economics, Vol. 100 No. 2, pp. 253-267.

López-Mesa, B., Mulet, E., Vidal, R. and Thompson, G. (2011), "Effects of additional stimuli on idea-finding in design teams", Journal of Engineering Design, Vol. 22 No. 1, pp. 31-54. https://doi.org/10.1080/09544820902911366

Mumford, M.D. (2003), “Taking stock in taking stock”, Creativity Research Journal, Vol. 15, pp. 147-151.

Nagai, Y., Taura, T. and Mukai, F. (2009), "Concept blending and dissimilarity: Factors for creative concept generation process”, Design Studies, Vol. 30 No. 6, pp. 648-675. https://doi.org/10.1016/j.destud.2009.05.004

O'Quin, K. and Besemer, S.P. (1989), “The development, reliability, and validity of the revised creative product semantic scale", Creativity Research Journal, Vol. 2 No. 4, pp. 267-278. 10.1080/10400418909534323

Osborn, A.F. (1979), Applied Imagination: Principles and Procedures of Creative Problem-Solving, 3 edn, Charles Scribener's Sons, New York, USA.

Sarkar, P. and Chakrabarti, A. (2011), “Assessing design creativity”, Design Studies, Vol. 32 No. 4, pp. 348383. https://doi.org/10.1016/j.destud.2011.01.002

Shah, J.J., Smith, S.M. and Vargas-Hernandez, N. (2003), "Metrics for measuring ideation effectiveness", Design Studies, Vol. 24 No. 2, pp. 111-134. 10.1016/s0142-694x(02)00034-0

Shi, F., Chen, L., Han, J. and Childs, P. (2017), "A data-driven text mining and semantic network analysis for design information retrieval”, Journal of Mechanical Design, Vol. 139 No. 11, pp. 111402-111414. https://doi.org/10.1115/1.4037649

Simonton, D.K. (2017), "Domain-general creativity: On Generating Original, Useful, and Surprising Combinations", In: Kaufman J.C., Glaveanu V.P. and B. J. (eds), The Cambridge Handbook Of Creativity across Domains, The Cambridge University Press., Cambridge, UK, pp. 18-40.

Sio, U.N., Kotovsky, K. and Cagan, J. (2015), "Fixation or inspiration? A meta-analytic review of the role of examples on design processes", Design Studies, Vol. 39, pp. 70-99. https://doi.org/10.1016/j.destud.2015.04.004

Sternberg, R.J. and Lubart, T.I. (1998), “The Concept of Creativity: Prospects and Paradigms”, In: Sternberg, R.J. (ed.), Handbook of Creativity, Cambridge University Press, Cambridge, pp. 3-15.

Suzuki, W.A. (2005), “Associative learning and the hippocampus”, Psychological Science Agenda. American Psychological Association.

Taura, T. and Nagai, Y. (2013), “A systematized theory of creative concept generation in design: First-order and high-order concept generation”, Research in Engineering Design, Vol. 24 No. 2, pp. 185-199. https://doi.org/10.1007/s00163-013-0152-6

Taura, T., Nagai, Y., Morita, J. and Takeuchi, T. (2007), “A Study on Design Creative Process Focused on Concept Combination Types in Comparison With Linguistic Interpretation Process", Proceedings of the 16th International Conference on Engineering Design ICED07.

Vattam, S., Wiltgen, B., Helms, M., Goel, A.K. and Yen, J. (2011), "DANE: Fostering Creativity in and through Biologically Inspired Design”, Design Creativity 2010. Springer, London, pp. 115-122.

Wang, H.-H. (2016), "Winning formulas for metaphor design: A case study of design competitions", DS 84: Proceedings of the DESIGN 2016 14th International Design Conference.

Wang, H.-H. and Chan, J.-H. (2010), “An Approach to Measuring Metaphoricity of Creative Design”, In: Taura, T. and Nagai, Y. (eds), Design Creativity 2010, Springer London, London, pp. 89-96.

Ward, T.B. (1994), "Structured imagination: the role of category structure in exemplar generation", Cognitive Psychology, Vol. 27 No. 1, pp. 1-40. https://doi.org/10.1006/cogp.1994.1010

Ward, T.B. (1995), “What's old about new ideas?", In: The Creative Cognition Approach., The MIT Press, Cambridge, MA, US, pp. 157-178.

Ward, T.B. and Kolomyts, Y. (2010), “Cognition and Creativity”, In: Kaufman, J.C. and Sternberg, R.J. (eds), The Cambridge Handbook of Creativity, The Cambridge University Press, Cambridge, UK, pp. 93-112.

Yang, H. and Zhang, L. (2016), "Promoting creative computing: origin, scope, research and applications", Digital Communications and Networks, Vol. 2 No. 2, pp. 84-91.

Yilmaz, S., Daly, S.R., Seifert, C.M. and Gonzalez, R. (2016), "Evidence-based design heuristics for idea generation", Design Studies, Vol. 46, pp. 95-124. https://doi.org/10.1016/j.destud.2016.05.001

Zhai, L.-Y., Khoo, L.-P. and Zhong, Z.-W. (2009), "Design concept evaluation in product development using rough sets and grey relation analysis", Expert Systems with Applications, Vol. 36 No. 3, pp. 7072-7079. 